\title{
Emotional Intelligence and Academic Achievement among Advantage and Disadvantage Children
}

\author{
Dr. Smritikana Mitra Ghosh*
}

\begin{abstract}
:
In the present investigation an attempt has been made to reveal the relationship of emotional intelligence and academic achievement. It also studies the emotional intelligence and academic achievement of high and low socio economic status children. Sample for the study includes 200 (100 high socio economic status and 100 low socio economic status) of class Xth of Ranchi. The data were analyzed with the help of t-ratio and product moment coefficients of correlation. The findings of the study reveal positive relationship between emotional intelligence and academic achievement. The study also reveals that students with high and low socio economic status differ from one another on emotional intelligence and academic achievement.
\end{abstract}

Keywords: Emotional intelligence, Academic achievement, socio economic status

\section{INTRODUCTION}

The rapid development of the era is challenging the adolescents to face the wave of globalization. Thus, the ability to control the emotions has become important for not carried away by the flow of negative and evil elements.

Emotions have so much of power that in Latin they were described as 'motus anima', meaning literally the spirit that moves us. They serve as a powerful source of human energy. Emotions are an important part of life which seriously affects all aspects of life. Almost in every experience there is an affectionate emotional aspect and managing them can have a significant role in general health and particular emotional health. Emotional intelligence is a social intelligence identifying the ability to adjust one self's emotions with others. Emotional intelligence (EI) refers to the ability to perceive, control and evaluate emotions. Some researchers suggest that emotional intelligence can be learned and strengthened, while others claim it is an in born characteristic.

*Ph.D, Ranchi University, Ranchi, Jharkhand \& India

(C) 2014, S Ghosh; licensee IJIP. This is an Open Access Research distributed under the terms of the Creative Commons Attribution License (http://creativecommons.org/licenses/by/2.0), which permits unrestricted use, distribution, and reproduction in any Medium, provided the original work is properly cited. 


\section{The Four Branches of Emotional Intelligence}

Salovey and Mayer proposed a model that identified four different factors of emotional intelligence: the perception of emotion, the ability reason using emotions, the ability to understand emotion and the ability to manage emotions.

1. Perceiving Emotions: The first step in understanding emotions is to accurately perceive them. In many cases, this might involve understanding nonverbal signals such as body language and facial expressions.

2. Reasoning with Emotions: The next step involves using emotions to promote thinking and cognitive activity. Emotions help prioritize what we pay attention and react to; we respond emotionally to things that garner our attention.

3. Understanding Emotions: The emotions that we perceive can carry a wide variety of meanings. If someone is expressing angry emotions, the observer must interpret the cause of their anger and what it might mean.

4. Managing Emotions: The ability to manage emotions effectively is a key part of emotional intelligence. Regulating emotions, responding appropriately and responding to the emotions of others are all important aspect of emotional management.

The last decade of $20^{\text {th }}$ century is infact considered to be the best gift to the international community of psychological sciences, as it is known for the best discovery related to emotional intelligence.

Academic achievement occupies a very important place in education as well as in the learning process. In our society academic achievement is considered as a key criterion to judge one's total potentialities and capacities. Now a days, achievement and evaluations are interpreted in terms of not only IQ but other factors also like social intelligence, emotional intelligence, spiritual and creativity and in terms of so many aspects. Children's performances and abilities are judged through covering various traits of personality. Academic achievement also denotes the knowledge attained and skill developed in the school subject, usually designed by the test scores. Academic achievement has been a topic of considerable interest and research for a very long time. Academic achievement has always been considered to be a very important factor in the educational life of an individual, because good academic record over years predicts future success of a person. The importance of prediction of academic achievement has increased during recent years because of various reasons. Academic achievement is often adversely affected by lack of social acceptance. Those who are well accepted, perform better than those who are neglected and much better than who are actually rejected. Poor academic work is common among those who are resentful because they do not receive the social acceptance they crave. 
Although some students try to compensate for lack of social acceptance by high academic achievement, this is a far less common source of motivation than is social acceptance.

Emotional intelligence and academic achievement have become a prime interest for the teachers, educationists, psychologists and parents to predict children's academic success which is considered to be an outcome of the learning environment as well as cognitive and intellectual potentials of adolescents.

\section{REVIEW OF LITERATURE}

Emotional intelligence is a dynamic construct influenced by diverse biological, psychological, and social factors. Numerous studies were intended to find out the impact of demographic variables on emotional intelligence of individuals. An exploratory study of the relationship between emotional intelligence and socio economic status was done by Holmes (2007) in which emotional intelligence was considered as criterion variable and socio-economic status as predictor, and measured by household income, parent education and occupation. Bivariate and multivariate correlational analysis revealed significant positive relationship except mother's occupation and household income. Further Namdar, Sahebihagh, Ebrahimi and Rahmani (2008) have found a significant relationship between emotional intelligence score and the student's satisfaction of their family socioeconomic status among nursing students. The relationship between emotional intelligence and socio economic status was studied by Jacques (2009) among 221 college students and the study reported that socio economic status did not predicted emotional intelligence. Mohanty and Devi, L. (2010) in their study, revealed that good education and occupation of parents in positively and significantly effects the interpersonal relationship of the adolescents. It means that parents having good occupation have adolescents having the ability in establishing and maintaining mutually satisfying relationship characterized by emotional closeness and intimacy. Chopera (1982), has found that socio - economic background was a very important determinant for continuation of education and students belonging to higher socio-economic class had higher academic achievement and vice versa. The same was supported by Kapoor (1987). More recently, a small body of empirical research has emerged to suggest that there is merit to the idea that emotional intelligence is associated with academic achievement - as long as careful attention is directed at the methodology for assessing emotional intelligence and achievement variables (Parker, Summerfeldt, Hogan, \& Majeski, 2004). Petrides, Frederickson, and Furnham (2004) examined the relationships among emotional intelligence, cognitive ability, and academic performance in a British sample of 650 Grade 11 students. They found that emotional intelligence moderated the relationship between academic performance and cognitive ability. Parker et al. (2004) study by examining the relationship between emotional intelligence and academic achievement in younger respondents. Petrides, Frederickson, and Furnham (2004) looked at the relationships between trait emotional intelligence, academic performance, and cognitive ability in a sample of 650 British secondary education students (Grade 11). They found that emotional intelligence moderated the relationship between academic performance and cognitive ability. In a study conducted by Parker et al. (2004), various dimensions of emotional intelligence were found to be predictors of 
academic success. Family background has repeatedly proven to be a strong predictor of academic achievement. A central conclusion of the Coleman Report (1966) was that family background accounted for the majority of the variation in student achievement. Currie and Thomas (1999) show that socio-economic status and early child test scores are positively and significantly related.

Mayer (2001) finds that the increase in economic segregation between 1970 and 1990 "raised educational attainment among high-income children by about the same amount that it reduced educational attainment among low-income children."Extensive research in the sociology of education offers conclusive evidence of a positive relationship between family socio-economic status (SES) and the academic achievement of students (Sirin, 2005; White, 1982).

\section{HYPOTHESES}

1. There would be no significance of difference among advantage and disadvantage children in terms of emotional intelligence.

2. There would be no significance of difference among advantage and disadvantage children in terms of academic achievement.

3. There exists significant relationship between academic achievement and emotional intelligence.

\section{SAMPLE}

Sample of 200 school students of class $\mathrm{X}^{\text {th }}$ studying in the private and government schools of Ranchi town. The sample split of 100 students from high socio economic status (50 boys and 50 girls) and 100 students from low socio economic status (50 boys and 50 girls). income).

The high socio-economic group was taken from families with high income (Taxable

The Low socio-economic group was taken from families with very low income (Below the Poverty Line).

\section{INSTRUMENT}

1. Emotional Intelligence Inventory developed by Mangal and Mangal (2009) was used to mea sure emotional intelligence of the school students. The reliability by split half method was 0.89 and test retest method was 0.92 . The validity of the test was 0.613 .

2. The aggregate marks obtained by the students in their previous examination were considered as the academic achievement score.

\section{PROCEDURE}

The Emotional Intelligence Inventory was administered to both groups with instructions to complete all questions honestly and not to discuss the questions with fellow students. Scoring 
was done according to the respective scoring keys. In order to fulfill the hypotheses of the study the score obtained were analysized with mean, SD's and t value. To find out the relationship between academic achievement and emotional intelligence product moment correlation coefficient was computed.

\section{RESULTS}

Table - 1, Mean scores, SD's and " $t$ " value of the high and low socio-economic groups on emotional intelligence.

\begin{tabular}{|c|c|c|c|c|c|c|c|}
\hline Groups & N & Mean & SDs & SEM & Md & t & P Value \\
\hline High Socio-economic group & 100 & 49.53 & 4.64 & 0.35 & & & \\
\hline Low Socio-economic group & 100 & 47.73 & 3.67 & 0.22 & & & \\
\hline
\end{tabular}

It is evident from table -1

The both high and low socio-economic groups differed significantly in terms of emotional intelligence. Thus, the null hypothesis "There would be no significance of difference among advantage and disadvantage children in terms of emotional intelligence" is rejected.

The high socio-economic status students have higher level of Emotional intelligence than low socio-economic status students. The results are in agreement with the findings of the earlier researches: (Hossein Namdar, et.al 2008), (Kaur and Jaswal 2005 and Ozabaci, 2006). Hossein Namdar et.al 2008 found that there was a significant relationship between emotional intelligence score and the student's satisfaction of their family socio- economic status. Kaur and Jaswal 2005 found that there was a significant relation between emotional intelligence score and students satisfaction of their family socio-economic status. The significant and positive relationship was found between high performance for strategic emotional intelligence and family climate. 
Table - 2, Mean scores, SD's and “t”" value of the high and low socio-economic groups on academic achievement.

\begin{tabular}{|c|c|c|c|c|c|c|c|}
\hline Groups & N & Mean & SDs & SEM & Md & t & P Value \\
\hline High Socio-economic group & 100 & 46.56 & 11.74 & 2.3 & & & \\
\hline Low Socio-economic group & 100 & 39.56 & 11.31 & 2.13 & & & \\
\hline
\end{tabular}

Table -2 shows that

There is a difference between high and low socio-economic groups on the academic achievement. The result revealed that the academic achievements of high socio-economic group were much better than that of low socio-economic group. Family background has repeatedly proven to be a strong predictor of academic achievement. The results are in agreement with the findings of the earlier researches: Currie and Thomas (1999) Hoxby (2001).

Table - 3, Correlation co-efficient of academic achievement with emotional intelligence.

$$
\mathrm{N}=200
$$

\begin{tabular}{|l|c|c|}
\hline & Academic Achievement & P value \\
\hline Emotional Intelligence & $0.330479152^{* *}$ & 0.01 \\
\hline
\end{tabular}

Result of the present study revealed that emotional intelligence had a significant correlation with academic achievement. Hence, the hypothesis "There exists significant relationship between academic achievement and emotional intelligence" is accepted. This result is consistent with the earlier research findings of the Schuttle et.al (1998) and Topia (1998) who found a significant relationship between emotional intelligence and academic achievement. The effect of emotional intelligence on academic achievement is well documented in the literature (Bar - On, 2003; Farook, 2002; Marquez et.al.2006 \& Adeyemo, 2007). 
Emotional Intelligence and Academic Achievement among Advantage and Disadvantage Children

\section{CONCLUSIONS}

1. High socio-economic group is having higher level of emotional intelligence rather than low socio-economic group.

2. High socio-economic group is having higher academic success rather than low socioeconomic group in same academic categories.

3. Emotional intelligence is positively and significantly co-related with academic achievement.

\section{REFERENCES}

1. Adeyemo, D. A. (2007). Moderating influence of emotional intelligence on the line between academic self - efficiency and achievement at University students. Psychology and Developing Societies. 19 (2) 199 - 213.

2. Bar - On. R. (2003).How important is it to educate people to be emotionally and socially intelligent and can it be done? Perspective in Education. 21(4), 3 - 13.

3. Coleman, James S. (1966). Equality of Educational Opportunity, Washington, DC: US Department of Health, Education, and Welfare.

4. Currie, Janet and Duncan Thomas (2001), "Early Test Scores, Socioeconomic Status, School Quality and Future Outcomes," Research in Labor Economics, 20.

5. Farook. A. (2002).The effect of emotional intelligence on academic performance. Unpublished Ph.D.thesis. University of Karachi. Karachi.

6. Hossein, N, Mohammad S, Hossein .E \& Azad, R. (2008). Assessing emotional intelligence and its relationship with demographic factors of nursing students. IJNMR, Autumn, 13 (4) 145-149.

7. Hoxby, Caroline M. (2001), "If Families Matter Most, Where Do Schools Come In?," in A Primer on America's Schools, ed. Terry M. Moe, Stanford, CA: Hoover Institution Press, 89-126.

8. Jacques, E. T. (2009). The Relationships between Emotional Intelligence and the Academic Performance and Selection of a Major of College Students.

9. Kapoor, R. (1987). Study of factors responsible for high and low achievement at junior High school level. 4th survey of Educational Research. (1) 829- 830.

10. Kaur, R and Jaswal, S. (2005). Relationship between strategic emotional intelligence and family climate of Punjabi adolescents. Anthropologist, 7(4) 293-298.

11. Marquez, P. G. Martin, R. P \& Baracket, M. A.(2006).Relating emotional intelligence to social competence and academic achievement in high school students.Psichotema.18 (Supl), 18 - 23.

12. Mayer, S. (2001). "How Economic Segregation Affects Children's Educational Attainment," Harris School Working Paper.

13. Parker, J.D.A., Summerfeldt, L.J., Hogan, M.J., \& Majeski, S. (2004). Emotional intelligence and academic success: Examining the transition from high school to university. Personality and Individual Differences, 36, 163-172.

14. Petrides, K.V., Frederickson, N., \& Furnham, A. (2004). The role of trait emotional intelligence in academic performance and deviant behavior at school. Personality and Individual Differences, 36, 277-293.

15. Sirin, S. R. (2005). Socioeconomic status and academic achievement: A metaanalytic review of research. Review of Educational Research, 75(3), 417-453.

16. White, K. R. (1982). The relation between socioeconomic status and academic achievement. Psychological Bulletin, 91(3), 461-481. 